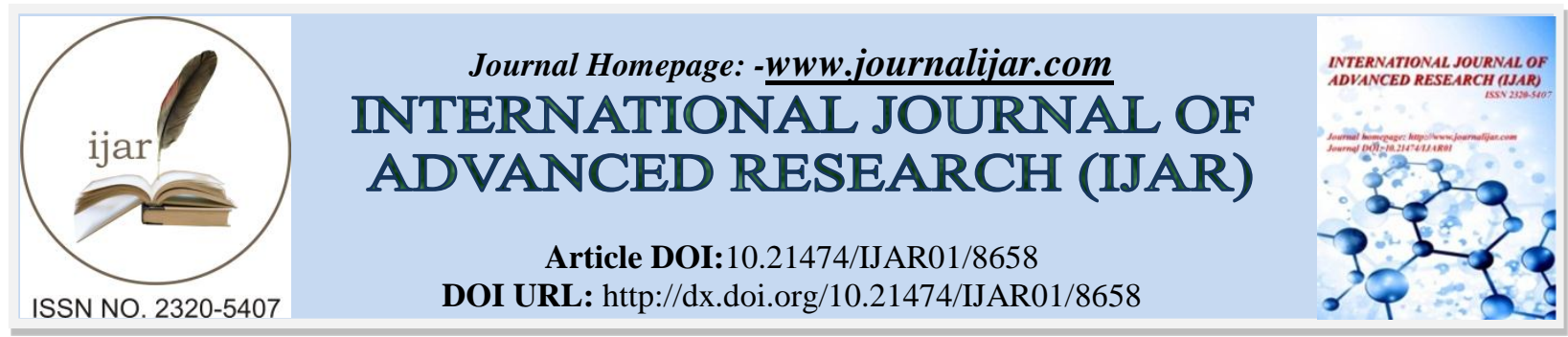

RESEARCH ARTICLE

\title{
COMMISSIONING OF FIRST STATE OF ART CLINAC DHX MEDICAL LINEAR ACCELERATOR AT SHER- I- KASHMIR INSTITUTE OF MEDICAL SCIENCES, J\&K: QUANTITATIVE AND QUALITATIVE DOSIMETRIC ANALYSIS.
}

M Mohib-ul Haq, Aijaz A Khan, Mohsin R Khan, Misba H Baba and Sajad A Rather. Department of Radiological Physics \& Bio-Engineering SKIMS, Srinagar, J\&K.

\section{Manuscript Info}

\section{Manuscript History}

Received: 09 January 2019

Final Accepted: 11 February 2019

Published: March 2019

Key words:-

Commisioning, Medical Linear

AcceleratorRadiotherapy,3DCRT,IMRT, IGR

\section{Abstract}

Objective: To provide a quantitative and qualitative dosimetric analysis of the results obtained while commissioning the first state of art Clinac DHX Medical Linear Accelerator at Sher- I- Kashmir Institute of Medical Sciences, J\&K.

Introduction: Radiotherapy is an important modality for cancer treatment management. Treatment of almost all the tumours of various shapes has become possible with modern radiotherapy techniques like 3DCRT, IMRT and IGRT etc. Response of radiation treatment is directly related to the precession in the delivered dose to the patient that in turn depends on the accuracy of the beam data used in the treatment planning process. This data is obtained during the commissioning of the Linear Accelerator (LINAC). The data generated thereof is used for the Treatment Planning System. Recently Sher-i-Kashmir Institute of Medical Sciences (SKIMS) procured its first Medical Linear accelerator (Clinac DHX) from Varian Medical Systems and the same was commissioned successfully. This study is inclined towards the evaluation of the various machine parameters and beam data generated for the said Linear accelerator.

Methodology: Various national and international protocols including TRS-398, AAPM TG-45 and IEC 60976 were followed to obtain the beam data and other machine parameters essential for precise dose delivery to the target volume. Data was generated for both photon and electron beams. Dosimetric equipments including RFA, Ionization Chambers, electrometers and various softwares provided by IBA were used extensively to generate the data. In order to carry out the commissioning of the Eclipse (version 13.6) Planning System, the beam data was generated in accordance to requirement of Anisotropic Analytical Algorithm (AAA) for photon beams and the Electron Monte Carlo (e-MC) for electron beams. Evaluation of the data was made on the basis of parameters like PDD, Dose Profiles, Flatness, Symmetry, Relative output factors, MU Linearity, Beam Quality, Collimator Transmission, Photon leakage, neutron leakage and DLG.

Results and conclusion: The results obtained for all the parameters including PDD, Dose Profiles, Flatness, Symmetry, Relative output 
Factors, MU Linearity, Beam Quality, Collimator Transmission, Photon leakage, neutron leakage and DLG were found to be in compliance with the standards set by various national and international bodies. The machine was therefore deemed to be fit and suitable for use in the cancer patients' treatment.

Copy Right, IJAR, 2019,. All rights reserved.

\section{Introduction:-}

Radiotherapy is an important modality for cancer treatment management. Treatment of almost all the tumours of various shapes has become possible with modern radiotherapy techniques like three dimensional conformal radiotherapy (3DCRT), intensity modulated radiotherapy (IMRT) and image guided radiotherapy (IGRT) etc. Response of radiation treatment is directly related to the precession in the delivered dose to the patient that in turn depends on the accuracy of the beam data used in the treatment planning process. This data is obtained during the commissioning of the Linear Accelerator (LINAC). Once the acceptance testing of the machine is done, commissioning, which is a process of obtaining beam data of the machine, is performed. It is mandatory to carry out all the commissioning tests before the machine is put for clinical use. The data generated thereof is used for the Treatment Planning System and other research purposes. Due to the non-availability of linear accelerators, telecobalt machines remained the only treatment modality in Radiation Oncology for a long period of 35 years in Kashmir. With the result patients would receive only conventional radiotherapy treatments here and modern treatment techniques like IMRT were not available. Recently Sher-i-Kashmir Institute of Medical Sciences (SKIMS) procured a Medical Linear accelerator (Clinac DHX) from Varian Medical Systems and the same was commissioned successfully. The machine has two X-Ray energies viz $6 \mathrm{MV}$ and $15 \mathrm{MV}$ and is also capable of generating five different electron energies viz 6,9,12, 16 \& $20 \mathrm{MeV}$. Treatment planning is computerised for both photon and electron beams. The exhaustive acceptance testing and Commissioning of the LINAC was carried out successfully by the Physicist team of SKIMS. This study is inclined towards the evaluation of the various machine parameters and beam data generated for the Linear accelerator (LINAC) Clinac-DHX installed at SKIMS.

\section{Material \& Methods:-}

Commissioning of the Clinac-DHX linear accelerator at SKIMS was performed by following the international practice and guidelines such as TRS-398, AAPM TG-45 and IEC 60976. Beam data was generated for photon beam energies of $6 \mathrm{MV}$ and $15 \mathrm{MV}$ and electron beam energies of 6, 9,12,16 and $20 \mathrm{MeV}$. IBA dosimetry system which includes RFA-Blue Phantom ${ }^{2}$ with Omni-Pro Accept 7.4C software was used for most of the dosimetric measurements. Measurements were carried out in water medium as human body contains around $80 \%$ water and it is a standard protocol worldwide. The RFA consists of a cubic water tank with inner dimensions of $40 \mathrm{x} 40 \mathrm{x} 40 \mathrm{~cm}^{3}$. The ionization chamber used for absolute dosimetry and other dosimetric measurements for photon beams was FC65G with serial number 2981(IBA Germany). Moreover two CC-13 chambers with serial numbers 13177 and 13178 were used for beam data collection and measurement of output factors. CC-13 chambers were used for output factor measurements so as to make sure that the sensitive volume of the chamber $(0.13 \mathrm{cc})$ comes well within smaller field sizes. Parallel plate ionization chamber PPC-05 with serial no. 843 (IBA Germany) was used for all electron beam measurements. The dosimeter used was Dose 1 Reference Class (IBA Germany). Precision barometer and thermometer were also used. Only half diagonal profiles were taken as the field size was exceeding the dimensions of the phantom at larger depths. The measurement of MLC dosimetric leaf gap (DLG) was carried out by using the procedure specified by Varian Medical Systems. In order to carry out the commissioning of the Eclipse (version 13.6) Planning System, the beam data was generated in accordance to requirement of Anisotropic Analytical Algorithm (AAA) for photon beams and the Electron Monte Carlo (e-MC) for electron beams.

\section{Central Axis Percentage Depth Dose (PDD)}

The first commissioning measurement was of the central axis Percentage Depth Dose (PDD). PDD is defined as the quotient (expressed as a percentage) of the absorbed dose at any depth $d\left(D_{d}\right)$ to the absorbed dose at a reference depth $d_{\text {ref }}\left(D_{\text {ref }}\right)$, along the central axis of the beam. The PDD measurements were made at $100 \mathrm{~cm}$ source to skin distance (SSD) with CC-13 ion chamber. The vertical depth of the ionization chamber in the water phantom was determined by measuring from the bottom of the meniscus of the water to the centre of the chamber. Chamber correction for effective point of measurement $\left(0.6 * r_{\text {cav }}\right)$ [1] was taken into account in a software setting itself. PDD values were measured over a range of field sizes from $4 \times 4 \mathrm{~cm}^{2}$ to $40 \times 40 \mathrm{~cm}^{2}$. Measurements were made up to a 
scanning depth of $35 \mathrm{~cm}$. All PDD curves were smoothened by least-square algorithm and were normalized at a depth of maximum $\left(\mathrm{d}_{\max }\right)$ to $100 \%$.

\section{Open field Depth Dose Profiles}

In-line, cross-line and diagonal beam profiles were measured for both the photon energies for various recommended field sizes at $\mathrm{d}_{\max }, 5 \mathrm{~cm}, 10 \mathrm{~cm}, 20 \mathrm{~cm}$ and $30 \mathrm{~cm}$ depths. Beam profile data were smoothened by median filter and then central axis correction was made. After that beam profiles were normalized to $100 \%$ at the central axis to their corresponding field size. Analysis of beam profiles was carried out through the AAPM TG-45 (IEC 60976) protocol [2]. According to AAPM TG-45 protocol Flatness can be specified as a maximum permissible percentage variation from the average dose across the central $80 \%$ of the full width at half maximum (FWHM) of the profile in a plane transverse to the beam axis. The beam flatness $F$ was assessed by finding the maximum $D_{\max }$ and minimum $D_{\min }$ dose point values on the beam profile within the central $80 \%$ of the beam width and then using the relationship:

$\mathrm{F}=100 *\left(\mathrm{D}_{\max }-\mathrm{D}_{\min }\right) /\left(\mathrm{D}_{\max }+\mathrm{D}_{\min }\right)$

Symmetry evaluation of the beams was done as per the recommendations of International Electro-technical Commission (IEC 60976,2008) [2].

\section{Relative Output factors}

Output factor (Scp) comprises of both collimator $(\mathrm{Sc}) \&$ phantom scatter factor $(\mathrm{Sp})$. Collimator scatter consists of photons scattered mainly from the collimator, but also possibly from the air and the flattening filter of a LINAC. Collimator scatter factor is a function of beam quality and field size, which increases with increasing field size. It is defined as the ratio of output in air for given field to the reference field size. Usually the reference field size is taken as $10 \times 10 \mathrm{~cm}^{2}$. Measurements were performed in the air at SAD $100 \mathrm{~cm}$ with sufficient build-up cap to provide charge particle equilibrium. Whereas phantom scatter factor, is defined as the ratio of output for the given field to reference field size at reference depth in water phantom under maximum scatter condition [3]. Phantom scatter factor was measured for various symmetric and asymmetric field sizes ranging from $4 \times 4 \mathrm{~cm}^{2}$ to $40 \mathrm{x} 40 \mathrm{~cm}^{2}$ for both $6 \mathrm{MV}$ and $15 \mathrm{MV}$ beams. Total phantom scatter factor was normalized at $10 \times 10 \mathrm{~cm}^{2}$ for all measured field sizes.

\section{MU Linearity}

The linearity of a monitor is defined as follows: if $\mathrm{L}$ is the reading on a calibrated dosimeter placed at calibration depth for calibration field size and $U$ is the corresponding Monitor chamber reading then the quotient of L \& U determines the monitor linearity response. This measurement is done with both gantry and collimator at $0^{\circ}$. By increasing the number of monitor units, there should be a corresponding increase in the meter reading. $6 \mathrm{MeV}$ energy in electron mode and $6 \mathrm{MV}$ energy in photon mode was used for the measurement of MU Linearity.

\section{Beam Quality}

As per TRS-398, the beam quality index for photon beams is represented in terms of a ratio called $\mathrm{TPR}_{20 / 10}$, where $\mathrm{TPR}_{20 / 10}$ is the ratio of the Tissue Phantom Ratios at the depths of 20 and $10 \mathrm{cms}$ respectively. The value of TPR $20 / 10$ can also be determined from the empirical formula $\mathrm{TPR}_{20 / 10}=1.2661 \times \mathrm{PDD}_{20,10}-0.0595, \mathrm{Where} \mathrm{PDD}_{20,10}$ is the ratio of PDD at $20 \& 10 \mathrm{~cm}$ depths respectively [4]. However $\mathrm{TPR}_{20 / 10}$ was measured directly in a $\mathrm{D}_{20 / 10}$ phantom in iso-centric setup for the standard field size of $10 \times 10 \mathrm{~cm}^{2}$. The values of quality index were measured for both the photon beams and compared with the values obtained from the empirical formula.

\section{Evaluation of collimator transmission}

A detector was placed in the plane normal to the radiation beam axis at the normal treatment distance by setting $\mathrm{X}$ collimators for minimum field size and Y collimators for maximum field size so that transmission occurred only through the pair of X collimators. Similarly another detector was placed by setting Y collimator for minimum field size and $\mathrm{X}$ collimator for maximum field size. The reading of the detectors shows the maximum leakage radiation through the $\mathrm{X}$ and $\mathrm{Y}$ collimators. For the measurement of absorbed dose due to collimator transmission (radiation leakage), detectors with build-up cap were placed at the point of maximum as well as uniform radiation leakage points. As the maximum square field size of radiation for this machine is $40 \mathrm{~cm} \times 40 \mathrm{~cm}$, which is more than $500 \mathrm{~cm}^{2}$, an additional condition of collimator transmission measurement must be applied. In this case, for the measurement of average absorbed dose due to leakage radiation through the beam limiting devices, 12 points were chosen. These points were: four points located on the two major axes at a distance of $1 / 3 \mathrm{R}$ from the radiation beam axis, and eight points located on the two major axes and on the two diagonals at a distance of $2 / 3 \mathrm{R}$ from 
the radiation beam axis. All values of the absorbed dose and area are referred to the NTD (see Fig. 1). The parameter R

Fig 1:-Radiation leakage measurement at 16 points in the plane of radius $2 \mathrm{~m}$ centered at isocenter and normal to the central beam axis is $\left\{(40 / 2)^{2}+(40 / 2)^{2}\right\}^{1 / 2}=28.28 \mathrm{~cm}$, which is the radius of the circle covering the maximum definable square field size (i.e. $40 \mathrm{~cm} \times 40 \mathrm{~cm}$ ). These measurements were carried for both $6 \mathrm{MV}$ and $15 \mathrm{MV}$ photon energies.

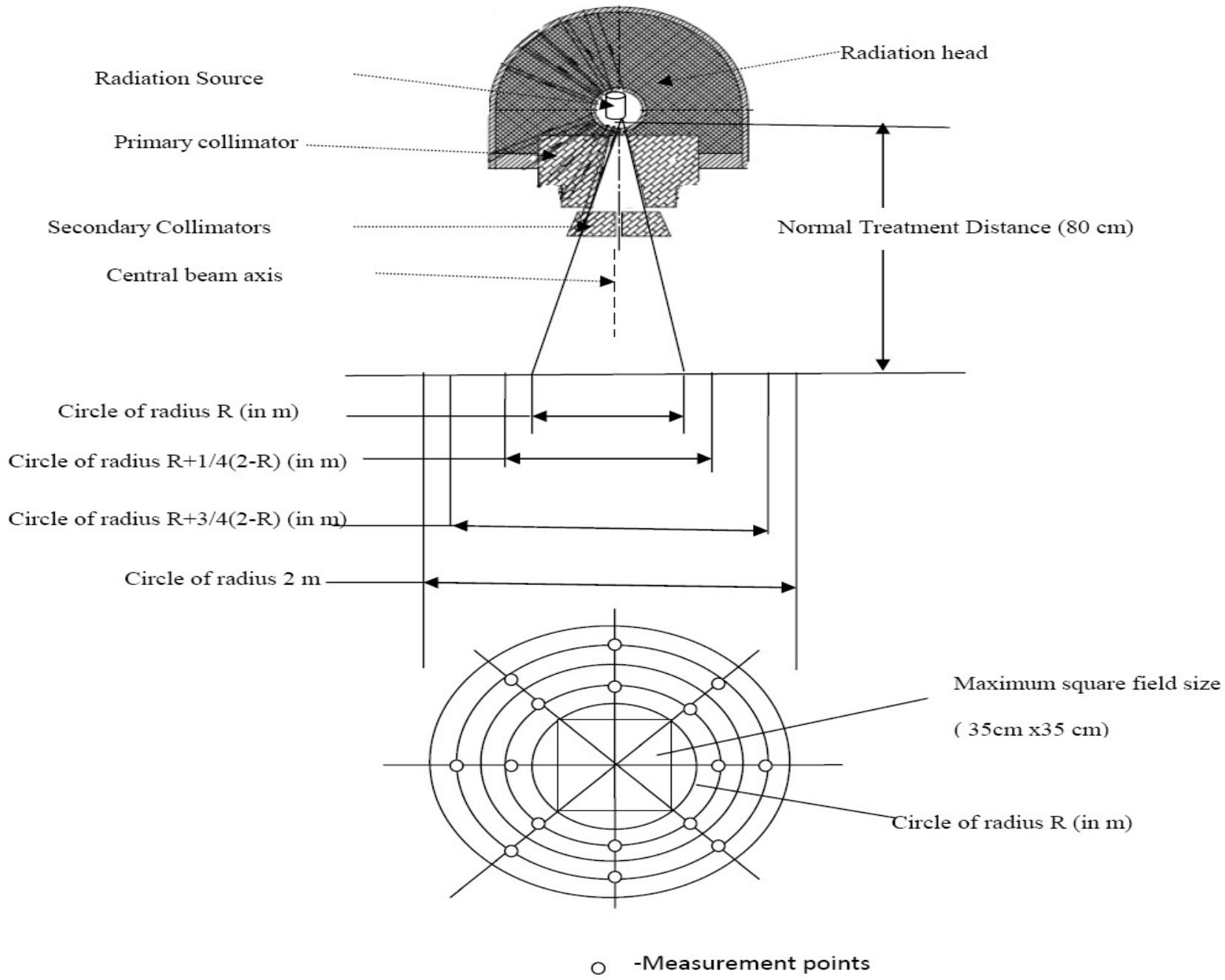

\section{Radiation leakage measurements in the patient plane}

A circular plane of radius $2 \mathrm{~m}$ centered on and normal to the central radiation beam axis at the normal treatment distance (NTD) and outside the area of the maximum radiation beam is called patient plane.[5] The detectors with build up cap were placed at the 16 test points as defined in Fig. 1 for radiation leakage measurement in the patient plane.

\section{Neutron Leakage}

Maximum and average neutron leakage in and outside the patient plane was measured for the maximum dose rate of $400 \mathrm{MU} / \mathrm{min}$ and photon beam energy of $15 \mathrm{MV}$. The readings were taken at different positions within and outside the patient plane.

\section{Interleaf and Intraleaf MLC leakage}

The intraleaf MLC leakage was measured in the Blue Phantom ${ }^{2}$ RFA by placing the chamber at $5 \mathrm{~cm}$ depth and a source to chamber distance of $100 \mathrm{~cm}$. The $\mathrm{CC}-13$ ion chamber was placed exactly beneath the projection of center 
of an MLC leaf. Meter readings were taken $10 \mathrm{~cm}$ off axis with MLCs fully closed. Then the chamber was taken to the next position by taking an increment of $1 \mathrm{~cm}$ with the help of the Omni-Pro software. An increment of $1 \mathrm{~cm}$ was chosen to keep the chamber exactly in the centre position of the next MLC leaf. Normalization was performed with an open MLC field size of 10x10 $\mathrm{cm}^{2}$. A dose rate of $400 \mathrm{MU} / \mathrm{min}$ was used for this measurement.

The interleaf transmission was measured by using the same procedure except that the chamber was placed in between two MLC leaves instead of placing it in the centre of a particular leaf projection.

\section{Dosimetric Leaf Gap (DLG)}

Varian linear accelerators have round shaped MLC leaves. Transmission through an end portion of the leaf causes a difference in optical and the actual radiation field defined by MLCs. In order to compensate for transmission through the end of a leaf, it is important to incorporate DLG value in TPS. DLG has relevance in IMRT and RapidArc planning where large numbers of MUs are delivered using various MLC shapes. DLG was measured as per the Varian procedure [6]. As recommended by Varian, DLG was measured in SAD setup at a depth of $5 \mathrm{~cm}$ deeper than the depth of possible electron contamination. Varian provided DICOM files which consisted of plans of programmed sliding MLC field gaps of $2 \mathrm{~mm}, 4 \mathrm{~mm}, 6 \mathrm{~mm}, 10 \mathrm{~mm}, 14 \mathrm{~mm}, 16 \mathrm{~mm}$ and 20 mm respectively. The Gap moved from $-60 \mathrm{~mm}$ to $+60 \mathrm{~mm}$ with constant speed with respect to MU. Average transmission for both the banks $\left(\mathrm{R}_{\mathrm{T}}\right)$ and meter reading for each moving gap size $(\mathrm{Rg})$ was measured. Contribution of average MLC leaf transmission to the gap $\left(\mathrm{R}_{\mathrm{gT}}\right)$ was calculated by using the formula:

$\mathrm{R}_{\mathrm{gT}}=\mathrm{R}_{\mathrm{T}} *[1-\mathrm{g}(\mathrm{mm}) / 120(\mathrm{~mm})]$

Where,

$\mathrm{R}_{\mathrm{gT}}=$ Average MLC transmission corresponding to gap $\mathrm{g}$.

$\mathrm{R}_{\mathrm{T}}=$ Average transmission $=\left(\mathrm{R}_{\mathrm{T}, \mathrm{A}}+\mathrm{R}_{\mathrm{T}, \mathrm{B}}\right) / 2$.

$\mathrm{g}=$ MLC gap size.

Corrected gap reading was calculated from each gap. Corrected gap is defined as follows:

$\mathrm{R}_{\mathrm{g}}{ }^{\prime}=\left(\mathrm{Rg}-\mathrm{R}_{\mathrm{gT}}\right)$

Where,

$\mathrm{R}_{\mathrm{g}}{ }^{\prime}=$ Corrected gap reading correspond to gap $\mathrm{g}$.

$\mathrm{Rg}=$ Meter reading with gap size $\mathrm{g}$.

Finally a graph was drawn between gap size $g$ and the corrected gap reading correspond to gap g ( $\mathrm{R}_{\mathrm{g}}$ '). It was observed that the downward extrapolation of the line intersects at $\mathrm{x}$-axis. The value at the point of intersection is defined as the leaf gap. Leaf gap measurement was performed for both the 6 and $15 \mathrm{MV}$ photon energies.

\section{Results and Discussion:-}

\section{Percentage Depth Dose}

The PDD values for both photon beams (6 MV and $15 \mathrm{MV}$ ) and for all electron energies were determined and are presented in table 1. The PDD values obtained for our case are matching well with the expected values. Therefore the evaluated data are in full compliance with the various published literature [7]. The measured depth dose curves of various field sizes for both 15MV and 6MV beam energies are respectively shown in Figure 2(a) and Figure 2(b). Similarly the measured PDD for various electron energies are given in Figure 2(c).

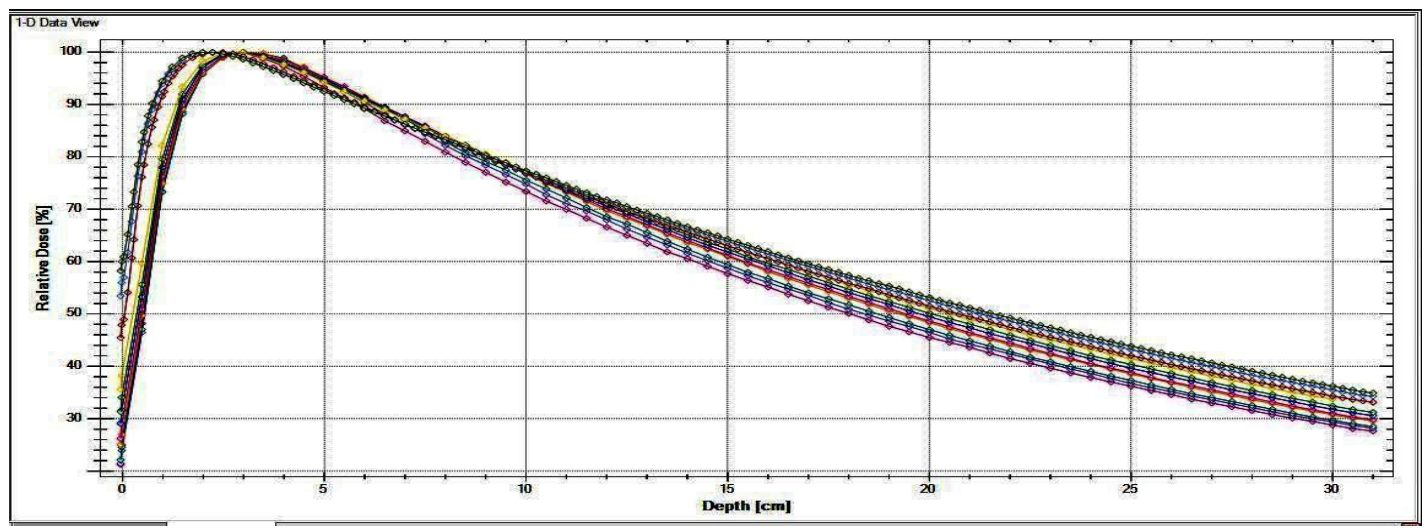

Fig 2a:-PDD of various Field sizes for 15MV Photon beam 


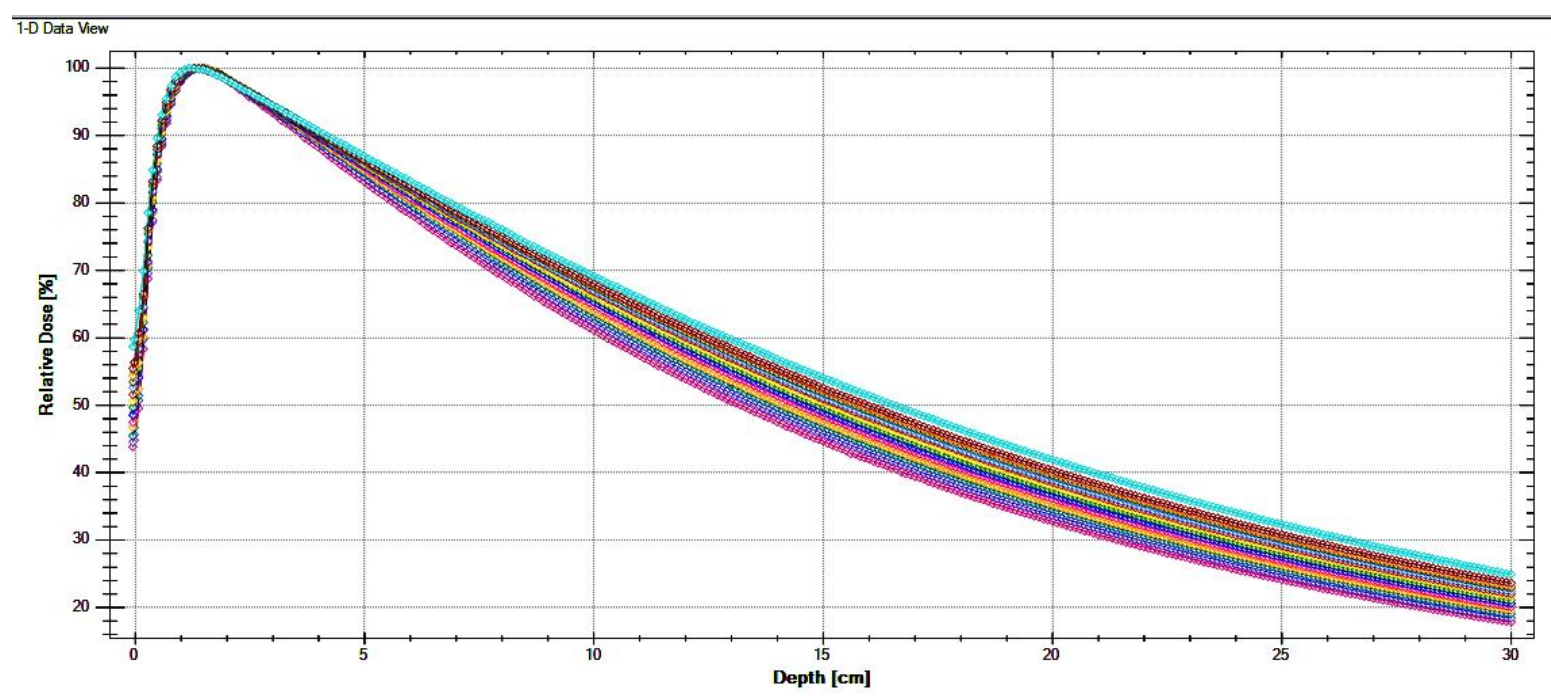

Fig 2 b:-PDD of various Field sizes for 6 MV photon beam

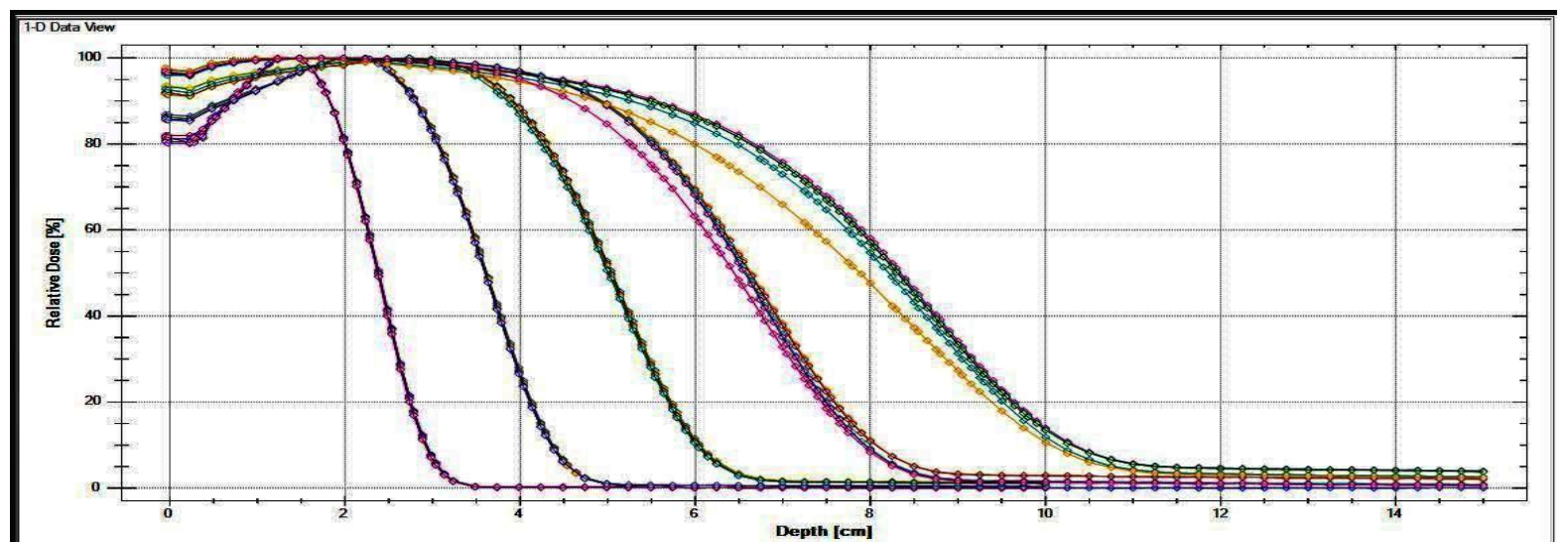

Fig 2c:- PDD of various Field sizes for $9 \mathrm{MeV}$ electron beam

\section{Beam flatness and symmetry.}

The values of beam flatness and symmetry obtained for various electron energies are shown in table 2. From table 2 , it can be seen that both beam flatness and symmetry for various electron energies are in comparable with the tolerance limits set by IEC 60976. Table 3 depicts the beam flatness and symmetry for both photon energies. Again the values obtained are in compliance with the standard limits [8]. Measured beam profiles of various field sizes for both 15MV and 6MV photon beam energies shown in Figure 3(a) and Figure 3(b). Similarly the Measured beam profiles for various field sizes for $9 \mathrm{MeV}$ electron energy is given in Figure 3(c).

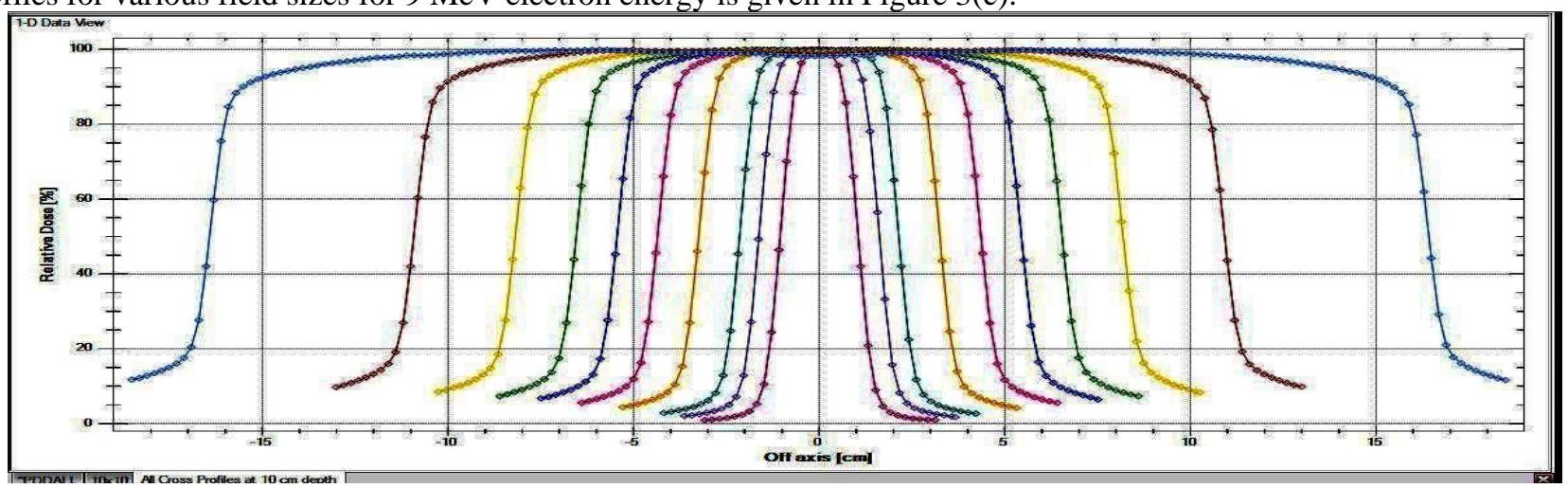

Figure 3a:-Beam profile of various field sizes for $6 \mathrm{MV}$ 


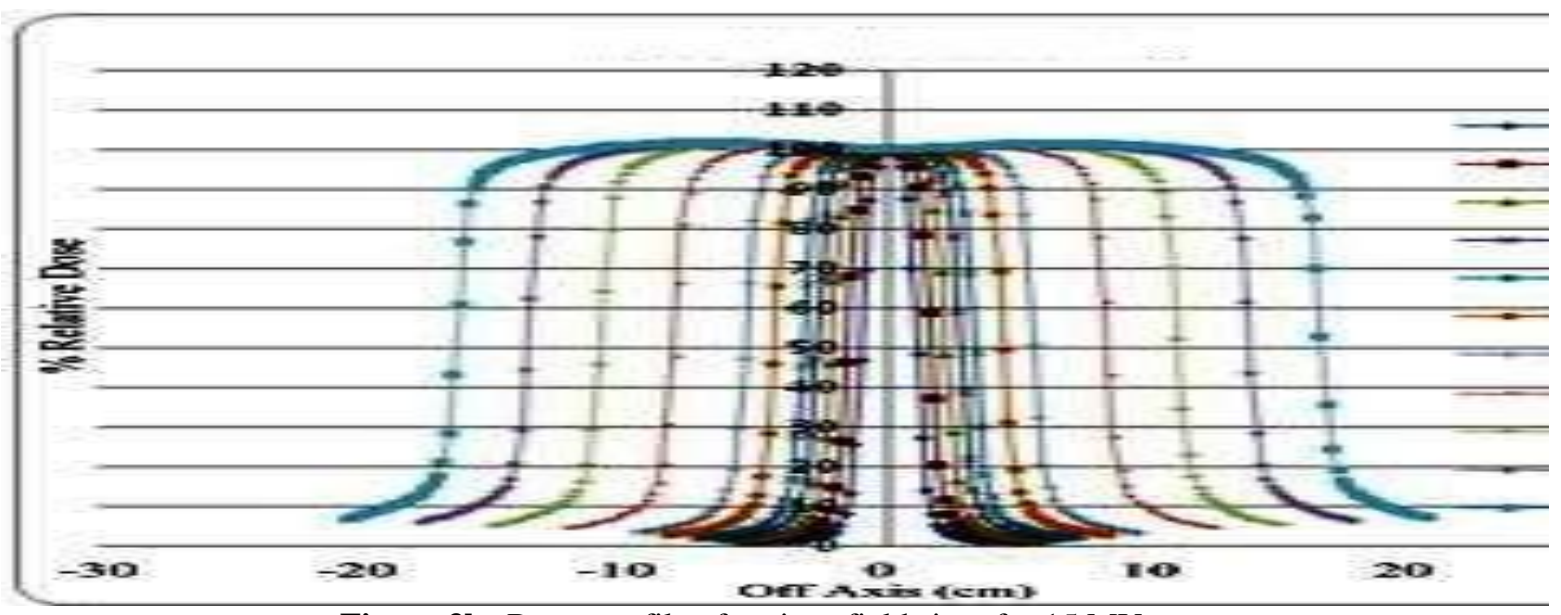

Figure 3b:-Beam profile of various field sizes for $15 \mathrm{MV}$

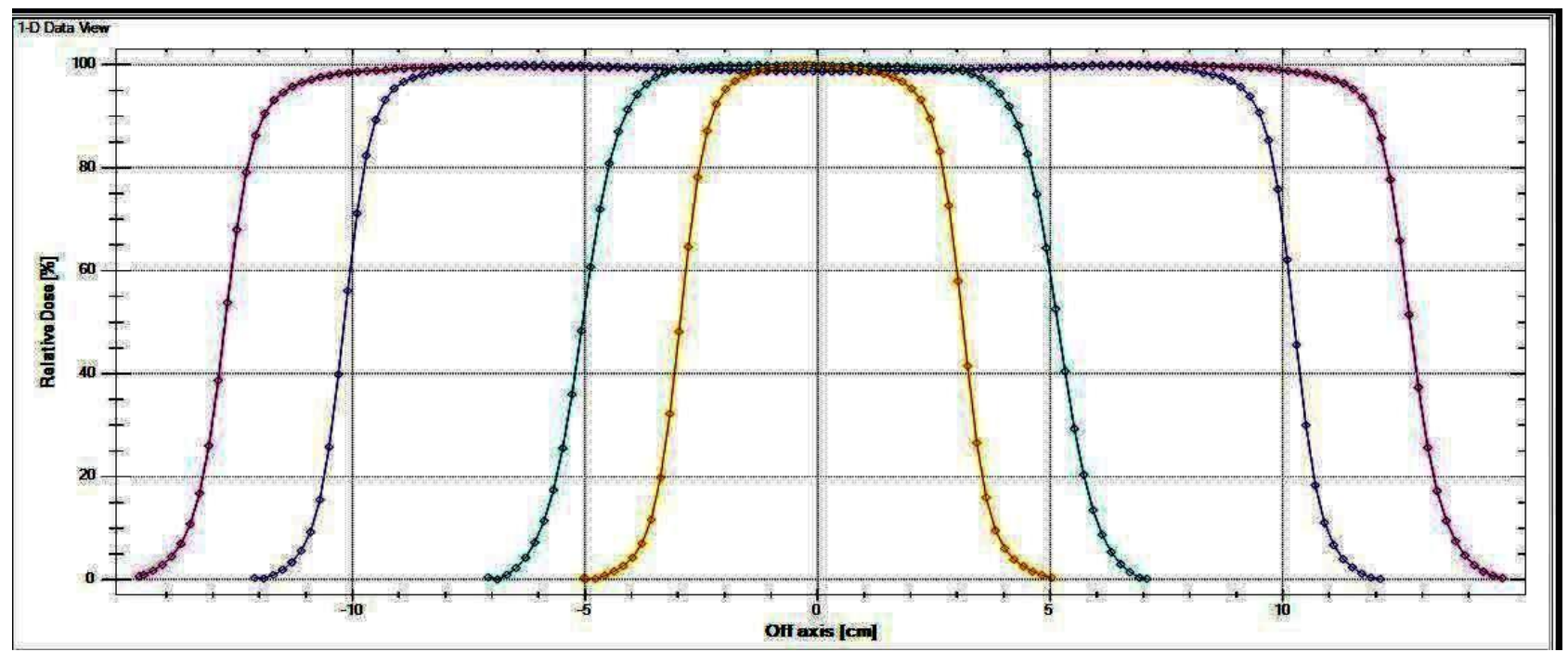

Figure 3c:-Beam profile of various field sizes for 9MeVelectron energy

\section{Collimator transmission}

The maximum collimator transmission through the $\mathrm{X}$ collimator and through the $\mathrm{Y}$ collimator obtained is well within the $2 \%$ of the maximum absorbed dose NTD for a $10 \mathrm{~cm} \times 10 \mathrm{~cm}$ field size. The collimator transmission was done for higher energy, that is, $15 \mathrm{MV}$ and the values obtained were $1.4 \%$ for $\mathrm{X}$ collimators and $1.2 \%$ for $\mathrm{Y}$ collimators.

\section{Leakage of radiation in patient plane.}

The maximum radiation leakage for $15 \mathrm{MV}$ obtained was $0.089 \%$ and an average radiation leakage was $0.032 \%$ of the maximum absorbed dose at NTD for $10 \mathrm{~cm} \times 10 \mathrm{~cm}$ radiation field size, while the maximum radiation leakage for $6 \mathrm{MV}$ obtained was $0.033 \%$ and an average radiation leakage was $0.014 \%$. Thus the results obtained are well below the permissible limit of $0.2 \%$ maximum radiation leakage and $0.1 \%$ average radiation leakage of the maximum absorbed dose at NTD for $10 \mathrm{~cm} \times 10 \mathrm{~cm}$ radiation field size.

\section{Neutron Leakage and Interleaf and Intraleaf MLC leakage}

The neutron leakage for $15 \mathrm{MV}$ beam was calculated and the maximum value obtained was $0.019 \%$ of the photon dose at NTD whereas the average value obtained was $0.0125 \%$. The value is well within the tolerance limit of $0.02 \%$ set by competent authority [9].

The interleaf and intra-leaf MLC leakage were measured and the values were $0.042 \%$ and $0.035 \%$ respectively. The values obtained were within tolerance limits of $3 \%$ and $2 \%$ respectively [10]. 


\section{Deviation in dose linearity}

Maximum deviation in dose linearity for $6 \mathrm{MV}$ and $15 \mathrm{MV}$ beams obtained are $0.30 \%$ and $-0.05 \%$ respectively whereas the maximum deviation in dose linearity for electron beams ranges from $9 \mathrm{MeV}$ and $16 \mathrm{MeV}$ electron beams are $1.60 \%$ to $1.91 \%$ respectively.

\section{Dosimetric Leaf Gap}

Calculated DLG parameters for measurement at lower energy $6 \mathrm{MV}$ and higher energy $15 \mathrm{MV}$ are given in table 3. The values obtained are in agreement as stated by the manufacturer.

\section{Beam Quality and Penumbra.}

The beam quality index for both photon energies and percentage deviation in their values are presented in table 4 . The penumbra values for all electron energies and the both photon energies are given in table 1 and table 2 respectively and the values obtained were in compliance with the standard limits set by competent authority.

\section{Conclusion:-}

From our systematic study of the various parameters of the first state of art linear accelerator procured from M/S Varian Medical Systems Pvt. Ltd, installed at the tertiary care hospital, SKIMS, Srinagar, while following the internationally established protocols, it was observed that the results obtained thereof were well within the tolerance limits prescribed by Atomic Energy Regulatory Board (the regulatory authority in India) and other international organisations like IEC, AAPM etc.. The results obtained were deemed to be in close agreement with the internationally

established

standards.

Table1:-Depth of maximum dose and PDD for $10 \mathrm{x} 10 \mathrm{~cm}^{2}$ field size.

\begin{tabular}{|c|c|c|c|}
\hline Sr.No. & Beam energy & $\begin{array}{l}\text { Depth of maximum absorbed for } \\
\text { Photons and } \mathbf{Z}_{\text {ref }} \text { for Electrons at } \\
\text { SSD } 100 \mathrm{~cm} \text { in water. }\end{array}$ & $\begin{array}{l}\text { PDD value for } 10 \mathrm{~cm} \times 10 \mathrm{~cm} \text { field } \\
\text { size }\end{array}$ \\
\hline 1 & $6 \mathrm{MV}$ (Photon) & $1.48 \mathrm{~cm}\left(\right.$ For $\left.10 \mathrm{x} 10 \mathrm{~cm}^{2}\right)$ & $66.80 \%$ (at $10 \mathrm{~cm}$ depth) \\
\hline 2 & $15 \mathrm{MV}$ (photon) & $2.98 \mathrm{~cm}\left(\right.$ For $\left.10 \times 10 \mathrm{~cm}^{2}\right)$ & $77.00 \%$ (at $10 \mathrm{~cm}$ depth) \\
\hline 3 & $6 \mathrm{MeV}$ (Electron) & $1.26 \mathrm{~cm}\left(\right.$ For $\left.10 \times 10 \mathrm{~cm}^{2}\right)$ & $0.2 \%$ (at $5 \mathrm{~cm} \mathrm{depth)}$ \\
\hline 4 & $9 \mathrm{MeV}$ (Electron) & $2.02 \mathrm{~cm}\left(\right.$ For $\left.10 \times 10 \mathrm{~cm}^{2}\right)$ & $0.9 \%$ (at $5 \mathrm{~cm}$ depth) \\
\hline 5 & $12 \mathrm{MeV}$ (Electron) & $2.89 \mathrm{~cm}\left(\right.$ For $\left.10 \times 10 \mathrm{~cm}^{2}\right)$ & $51.3 \%$ (at $5 \mathrm{~cm}$ depth) \\
\hline 6 & $16 \mathrm{MeV}$ (Electron) & $3.89 \mathrm{~cm}\left(\right.$ For $\left.10 \times 10 \mathrm{~cm}^{2}\right)$ & $88.7 \%$ (at $5 \mathrm{~cm}$ depth) \\
\hline 7 & $20 \mathrm{MeV}$ (Electron) & $4.91 \mathrm{~cm}\left(\right.$ For $\left.10 \times 10 \mathrm{~cm}^{2}\right)$ & $91.5 \%$ (at $5 \mathrm{~cm}$ depth) \\
\hline
\end{tabular}

Table2:-Beam flatness, symmetry, penumbra and maximum deviation in dose linearity for various electron beam energies.

\begin{tabular}{|l|l|l|l|l|l|l|}
\hline Sr.No & $\begin{array}{l}\text { Electron } \\
\text { beam } \\
\text { energy }\end{array}$ & $\begin{array}{l}\text { Field size } \\
\text { (SSD=100cm) }\end{array}$ & Beam Flatness & Beam Symmetry & $\begin{array}{l}\text { Maximum } \\
\text { deviation in } \\
\text { dose } \\
\text { linearity }\end{array}$ & Penumbra \\
\hline 1. & $6 \mathrm{MeV}$ & $\begin{array}{l}10 \mathrm{~cm} \times 10 \mathrm{~cm} \\
\text { Depth }=1 \mathrm{~cm}\end{array}$ & $\begin{array}{l}\text { Inplane } 5.8 \mathrm{~mm} \\
\text { Crossplane } 7 \mathrm{~mm}\end{array}$ & $\begin{array}{l}\text { Inplane } 0.7 \% \\
\text { Crossplane } 1.3 \%\end{array}$ & $1.80 \%$ & $8.8 \mathrm{~mm}$ \\
\hline 2. & $9 \mathrm{MeV}$ & $\begin{array}{l}10 \mathrm{~cm} \times 10 \mathrm{~cm} \\
\text { Depth }=1 \mathrm{~cm}\end{array}$ & $\begin{array}{l}\text { Inplane } 3.2 \mathrm{~mm} \\
\text { Crossplane } 6 \mathrm{~mm}\end{array}$ & $\begin{array}{l}\text { Inplane } 0.8 \% \\
\text { Crossplane } 0.6 \%\end{array}$ & $1.60 \%$ & $6.4 \mathrm{~mm}$ \\
\hline 3. & $12 \mathrm{MeV}$ & $\begin{array}{l}10 \mathrm{~cm} \times 10 \mathrm{~cm} \\
\text { Depth }=2 \mathrm{~cm}\end{array}$ & $\begin{array}{l}\text { Inplane } 4.6 \mathrm{~mm} \\
\text { Crossplane } 7 \mathrm{~mm}\end{array}$ & $\begin{array}{l}\text { Inplane } 0.5 \% \\
\text { Crossplane } 1.2 \%\end{array}$ & $1.72 \%$ & $8.2 \mathrm{~mm}$ \\
\hline 4. & $16 \mathrm{MeV}$ & $\begin{array}{l}10 \mathrm{~cm} \times 10 \mathrm{~cm} \\
\text { Depth }=2 \mathrm{~cm}\end{array}$ & $\begin{array}{l}\text { Inplane } 2.3 \mathrm{~mm} \\
\text { Crossplane } 5.2 \mathrm{~mm}\end{array}$ & $\begin{array}{l}\text { Inplane } 0.4 \% \\
\text { Crossplane } 0.4 \%\end{array}$ & $1.91 \%$ & $6.6 \mathrm{~mm}$ \\
\hline 5. & $20 \mathrm{MeV}$ & $\begin{array}{l}10 \mathrm{~cm} \times 10 \mathrm{~cm} \\
\text { Depth }=2 \mathrm{~cm}\end{array}$ & $\begin{array}{l}\text { Inplane } 2.3 \mathrm{~mm} \\
\text { Crossplane } 5.2 \mathrm{~mm}\end{array}$ & $\begin{array}{l}\text { Inplane } 0.4 \% \\
\text { Crossplane } 0.4 \%\end{array}$ & $1.60 \%$ & $6.0 \mathrm{~mm}$ \\
\hline
\end{tabular}


Table 3:-Beam flatness, symmetry, penumbra, maximum deviation in dose linearity and DLG for various photon beam energies.

\begin{tabular}{|l|l|l|l|l|l|l|l|}
\hline Sr.No. & $\begin{array}{l}\text { Photon } \\
\text { beam } \\
\text { energy }\end{array}$ & $\begin{array}{l}\text { Field size } \\
\text { (SSD=100cm) }\end{array}$ & Beam Flatness & Beam Symmetry & $\begin{array}{l}\text { Maximum } \\
\text { deviation } \\
\text { in } \\
\text { linearity }\end{array}$ & Penumbra & DLG \\
\hline 1. & $6 \mathrm{MV}$ & $\begin{array}{l}10 \mathrm{~cm} \times 10 \mathrm{~cm} \\
\text { Depth }=5 \mathrm{~cm}\end{array}$ & $\begin{array}{l}\text { Inplane 1.6\% } \\
\text { Crossplane } \\
1.7 \%\end{array}$ & $\begin{array}{l}\text { Inplane } 1.1 \% \\
\text { Crossplane } 0.3 \%\end{array}$ & $0.30 \%$ & $8 \mathrm{~mm}$ & $1.8 \mathrm{~mm}$ \\
\hline 2. & $15 \mathrm{MV}$ & $\begin{array}{l}10 \mathrm{~cm} \times 10 \mathrm{~cm} \\
\text { Depth }=10 \mathrm{~cm}\end{array}$ & $\begin{array}{l}\text { Inplane } 2.2 \% \\
\text { Crossplane } \\
2.3 \%\end{array}$ & $\begin{array}{l}\text { Inplane } 1.7 \% \\
\text { Crossplane } 0.8 \%\end{array}$ & $-0.05 \%$ & $8.6 \mathrm{~mm}$ & $2.0 \mathrm{~mm}$ \\
\hline
\end{tabular}

Table 4:-

\begin{tabular}{|l|l|l|l|l|}
\hline Sr.No. & Photon Beam energy & $\begin{array}{l}\text { Value of } \\
\text { TPR }_{\mathbf{2 0} 1 \mathbf{1 0}} \\
\text { obtained. }\end{array}$ & $\begin{array}{l}\text { Value of TPR } \text { 20/10 }_{\text {given }} \\
\text { by the manufacturer. }\end{array}$ & $\begin{array}{l}\text { Percentage difference in } \\
\text { magnitude. }\end{array}$ \\
\hline 1 & $6 \mathrm{MV}$ & 0.666 & 0.676 & $1 \%$ \\
\hline 2 & $15 \mathrm{MV}$ & 0.759 & 0.756 & $0.3 \%$ \\
\hline
\end{tabular}

\section{References:-}

1. Das, I.J., Cheng, C.W., Watts, R.J., Ahnesjö, A., Gibbons, J., Li, X.A., Lowenstein, J., Mitra, R.K., Simon, W.E. and Zhu, T.C. (2008) Accelerator Beam Data Commissioning Equipment and Procedures: Report of the TG-106 of the Therapy Physics Committee of the AAPM. Medical Physics, 35, 4186-4215.

2. Nath, R., Biggs, P.J., Bova, F.J., Ling, C.C., Purdy, J.A., van de Geijn, J. and Weinhous, M.S. (1994) AAPM Code of Practice for Radiotherapy Accelerators: Report of AAPM Radiation Therapy Task Group No. 45. Medical Physics, 21, 1093-1121. (AAPM Report No. 47)

3. Khan, F.M. (2003) Physics of Radiation Therapy. 3rd Edition, Chapter No. 11, Lippincott Williams \& Wilkins.

4. Khan, F.M. (2003) Physics of Radiation Therapy. 3rd Edition, Chapter No. 10, Lippincott Williams \& Wilkins.

5. Medical Electrical Equipment Part 2-1: Particular requirements for the safety of electron accelerators in the range $1 \mathrm{MeV}$ to $50 \mathrm{MeV}$. IEC-60601-2-1. Geneva, Switzerland: International Electrotechnical Commission, 1998.

6. Dosimetric Leaf Gap Measurement, Procedure Recommended by Varian Medical System. Eclipse 10 Inverse Planning Administration and Physics rev. 6.1.1.

7. Gloria, P. (2013) Commissioning Measurements for Photon Beam Data on Three TrueBeam Linear Accelerators, and Comparison with Trilogy and Clinac 2100 Linear Accelerators. Journal of Applied Clinical Medical Physics, 14, 4077

8. "E.B Podgorsak", Radiation Oncology Physics." A handbook for Teacher and Students", Chapter No. 06. IAEA 2005.

9. Khan, F.M. (2003) Physics of Radiation Therapy, Wolters and Kluwer business, USA, 2010.

10. Khan, F.M. (2003) Physics of Radiation Therapy, $5^{\text {th }}$ Edition, Chapter 13, Wolters and Kluwer business. 